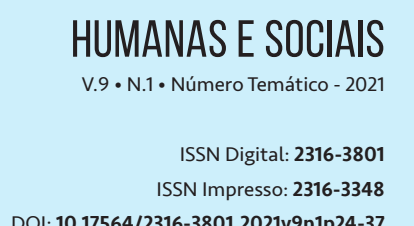

DOI: 10.17564/2316-3801.2021v9n1p24-37
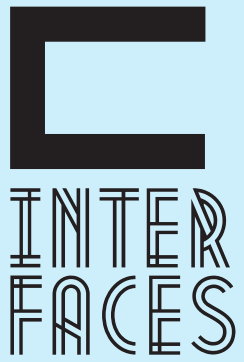

CIENTÍFICAS

\title{
DESENHO UNIVERSAL PARA MUSEUS: NOTAS SOBRE A ACESSIBILIDADE NOS ESPAÇOS CULTURAIS DA UNIVERSIDADE FEDERAL DE SERGIPE
}

\author{
UNIVERSAL DESIGN FOR MUSEUMS: NOTES ON \\ ACCESSIBILITY IN THE CULTURAL SPACES OF THE FEDERAL \\ UNIVERSITY OF SERGIPE
}

DISEÑO UNIVERSAL PARA MUSEOS: NOTAS SOBRE ACCESIBILIDAD EN ESPACIOS CULTURALES DE LA UNIVERSIDAD FEDERAL DE SERGIPE

Cristina de Almeida Valença Cunha Barroso Priscila Maria de Jesus ${ }^{2}$ Sura Souza Carmo ${ }^{3}$

NÚMERO TEMÁTICO:

"DEFICIÊNCIA, ACESSIBILIDADE E DIVULGAÇÃO CIENTíFICA"

\section{RESUMO}

A pesquisa traz reflexões iniciais sobre o papel e a presença do desenho universal em instituições museais no âmbito da Universidade Federal de Sergipe. Concebe e questiona a acessibilidade para além das barreiras de locomoção, ao levantar recursos pouco explorados e viáveis para implementação nas três instituições analisadas: 0 Museu Arqueológico de Xingó, o Centro de Cultura e Artes e o Museu do Homem Sergipano. Como metodologia optou-se pela pesquisa qualitativa, a qual foi apoiada no levantamento bibliográfico e visitas in loco. A pesquisa busca oferecer subsídios teóricos que possibilitem a reflexão e a ampla implementação de políticas assistivas dentro dos espaços museais sergipanos, para que se tornem espaços cada vez mais acessíveis para todos.

\section{PALAVRAS-CHAVE}

Desenho Universal. Acessibilidade. Museus. 


\section{ABSTRACT}

The research brings initial reflections on the role and the presence of universal design in museum institutions within the Federal University of Sergipe. It conceives and examines accessibility beyond locomotion barriers, by raising little explored and viable resources for implementation in the three analyzed institutions: The Archaeological Museum of Xingó, the Culture and Arts Center and the Museum of the Sergipe Man. As a methodology, qualitative research was chosen, which was supported by the bibliographic survey and on-site visits. The research seeks to offer theoretical subsidies that enable reflection and the broad implementation of assistive policies within the Sergipe's museum spaces, so that they become increasingly accessible spaces for everyone.

\section{KEYWORDS}

Universal Design. Accessibility. Museums.

\section{RESUMEN}

La investigación trae reflexiones iniciales sobre el papel y la presencia del diseño universal en las instituciones del museo dentro de la Universidad Federal de Sergipe. Concibe y cuestiona la accesibilidad más allá de las barreras locomotoras, al recaudar recursos poco explorados y viables para su implementación en las tres instituciones analizadas: el Museo Arqueológico de Xingó, el Centro de Cultura y Artes y el Museo del Hombre de Sergipe. Como metodología, optamos por la investigación cualitativa, que fue respaldada por la encuesta bibliográfica y las visitas in situ. La investigación busca ofrecer subsidios teóricos que permitan la reflexión y la amplia implementación de políticas de asistencia dentro de los espacios del museo de Sergipe, para que se conviertan en espacios cada vez más accesibles para todos.

\section{PALABRAS-CLAVE}

Diseño Universal. Accesibilidad. Museos 


\section{INTRODUÇ̄̃̃O}

Ninguém deveria deixar de conhecer e experimentar uma visita a um museu por falta de acesso. Afirma-se isso parafraseando Carl Sagan em O mundo assombrado pelos demônios quando ele reflete que "ninguém deveria deixar de aprender a ler por não ter acesso à educação" (SAGAN, 1996, p. 349). Uma afirmativa bastante coerente e compreensível, mas quando pensamos na estrutura social e no modo de vida atual percebemos diversos impeditivos às duas intenções: o acesso à cultura e à educação.

Quando se converge o olhar para os centros universitários esse desejo normalmente emerge com um tom mais politizado, haja vista a constante discussão acadêmica que envolve a questão de inclusão social e cultural. Discursos até por vezes entusiasmados são pronunciados em defesa da acessibilidade, prevendo a necessidade de implementar recursos específicos para atender a um tipo de público também específico. As tentativas com erros e acertos, sustentadas por essa visão, baseiam-se muito mais na ideia da diferença do que da inclusão.

Ao fundamentar as ações de inclusão cultural e social a partir da perspectiva da universalidade, onde as estratégias de acesso são para atender a todos, toma-se como base o coletivo e não o individual, permitindo, assim, uma maior possibilidade de proporcionar a inclusão. Entretanto, por mais produtivos e impactantes que sejam os debates e as produções científicas, ainda evidencia-se nos espaços culturais dos centros universitários barreiras físicas, comunicacionais e atitudinais que dificultam a integração e a inclusão (RIBEIRO, 2014; CIANTELLI, LEITE, 2016). Diante dessa evidência se questiona: Será que os espaços culturais da Universidade Federal de Sergipe (UFS) têm contribuído para promover a inclusão a todos os tipos de público?

Nessa direção, o presente artigo tem como objetivo investigar até que ponto as instituições culturais vinculadas à Universidade Federal de Sergipe podem ser consideradas acessíveis. Para essa pesquisa foram selecionados três espaços: o Museu Arqueológico de Xingó (MAX), o Centro de Cultura e Artes (CULTART) e o acervo do Museu do Homem Sergipano (MHS). Instituições que têm contribuído para o desenvolvimento do ensino, da pesquisa e da extensão, aproximando a comunidade da universidade por meio de ações educativas e exposições.

\section{APORTES TEÓRICOS}

O desenho universal compreende as ações que envolvem os diferentes tipos de acessibilidade e está relacionado à garantia de direitos dos indivíduos em serem tratados com igualdade, sendo fundamental o reconhecimento e atendimento de suas necessidades específicas (CAMARGO, 2017). As ações que envolvem a acessibilidade em edifícios públicos possuem longa data e engajamento de diversas entidades nacionais e internacionais. No âmbito brasileiro a Lei $n^{0} 10.098$ de 19 de dezembro de 2000 foi um marco, pois estabeleceu normas gerais e critérios básicos para a promoção da acessibilidade às pessoas portadoras de deficiência ou com mobilidade reduzida.

Interfaces Científicas - Humanas e Sociais • Aracaju • V.9 - N.1 • p. 24 - 37 • Número Temático - 2021 
Conforme a Lei nº 13.146 de 6 de julho de 2015, acessibilidade é a:

Possibilidade e condição de alcance para utilização, com segurança e autonomia, de espaços, mobiliários, equipamentos urbanos, edificações, transportes, informação e comunicação" incluindo ainda "sistemas e tecnologias, [....] outros serviços e instalações abertos ao público, de uso público ou privados de uso coletivo, tanto na zona urbana como na rural, por pessoa com deficiência ou com mobilidade reduzida. (BRASIL, 2015, on-line).

A acessibilidade é percebida por meios de princípios mais abrangentes que englobam além do aspecto físico, o comunicacional e o atitudinal. Alguns anos antes da Lei $n^{0} 13.146$ autores como Tojal (2007) advertiram que o estudo das barreiras atitudinais é tão importante quanto as outras dimensões. De acordo com Sassaki (2009) há diferentes dimensões da acessibilidade: arquitetônica, comunicacional, metodológica, instrumental, programática e atitudinal. No âmbito deste artigo será tratada, sobretudo, a acessibilidade comunicacional e como o desenho universal possibilita um padrão para os projetos que tornam ambientes acessíveis.

O conceito de desenho universal surgiu a partir das demandas de vários segmentos sociais, que na década de 1960 passaram a lutar por diversos direitos, entre eles de ambientes mais acessíveis (CARVALHO, 2005). A partir dos anos 1990, arquitetos e outros profissionais reuniram-se no Center for Universal Design, da Universidade da Carolina do Norte, nos Estados Unidos, estabelecendo os princípios do Desenho Universal (STAUT, 2014). O desenho universal é definido, segundo o Decreto $\mathrm{n}^{\circ} 5.296$ de 02/12/2004, como a "concepção de espaços, artefatos e produtos que visam atender simultaneamente todas as pessoas, com diferentes características antropométricas e sensoriais, de forma autônoma, segura e confortável, constituindo-se nos elementos ou soluções que compõem a acessibilidade".

Para Carvalho (2005, p. 6) o desenho universal é “importante e imprescindível” por ser uma "ferramenta para o planejamento de um meio urbano mais acessível e inclusivo". Para o autor são considerados os sete princípios do desenho universal: uso equitativo, flexibilidade no uso, uso simples e intuitivo, informação perceptível, tolerância de erros, pouco esforço físico e tamanho e espaço para aproximação e uso (CARVALHO, 2005; STAUT, 2014).

É importante ressaltar que independente do conceito adotado, o que se tem em vista é o pensamento de um desenho ou estratégias que diminuam as barreiras para o livre acesso aos espaços por pessoas com deficiência, ao permitir que todos possam usufruir dos espaços culturais em sua totalidade. Para Sassaki (2010) o desenho universal pode ser chamado também de "desenho para todos" ou "desenho inclusivo", pois inclui todas as pessoas, salientando que "os produtos e ambientes feitos com desenho universal ou inclusivo não parecem ser especialmente destinados a pessoas com deficiência” muitas vezes não perceptíveis por pessoas que não possua deficiência (SASSAKI, 2010, p. 151).

No entanto, quando se parte para os ambientes museais os produtos ou ambientes que precisam ser adaptados ganham maior destaque, uma vez que grande parte destas instituições são abrigadas em prédios históricos, com pouca ou nenhuma estrutura original pensada para a acessibilidade (REIS, 2015; MARTINS, 2017; SALASAR; MICHELON, 2020). Desta forma o Instituto do Patrimônio Histórico Nacional (IPHAN), acompanhando as discussões e tendo em vista a necessidade de se pen- 
sar os museus nacionalmente, instituiu a Instrução Normativa $n^{0} 1$ de 25 de novembro de 2003, que dispõe sobre a acessibilidade aos bens culturais imóveis sob a responsabilidade do poder federal.

Embora existam normas e leis para dispor sobre a acessibilidade em espaços culturais, parte dos espaços culturais da UFS carecem de um desenho universal que atenda a todos, que pense em outras barreiras no âmbito da acessibilidade que podem ser transpostas. Como ressalta Hughes, "eles não devem tender a criar exposições especiais para pessoas com deficiência, mas sim bom acesso por vários meios, incluindo 'tours de toque', ciclos de indução para surdos e bom planejamento de circulação" (HUGHES, 2010, p. 53, tradução nossa).

\section{MÉTODO}

A presente pesquisa foi estruturada no modo qualitativo para a interpretação do fenômeno, aqui entendido enquanto a discussão do desenho universal para os espaços museais da Universidade Federal de Sergipe. Como procedimentos foram adotados o levantamento bibliográfico, por meio de artigos, livros e dissertações, para o delineamento das ideias e construção do corpo teórico do trabalho. Foram analisados, ainda, documentos oficiais como leis e instruções normativas expedidos que versem sobre a acessibilidade para espaços culturais. Para análise dos espaços, utilizou-se a pesquisa in loco, com o registro fotográfico dos espaços expositivos e sua posterior descrição - com todas as ações realizadas no ano de 2018.

Para o estudo dos espaços foi criado um roteiro para a análise da acessibilidade nos espaços expositivos, sendo observadas barreiras físicas e atitudinais que impediam a circulação no local e um total usufruto da exposição. Foram fotografadas as barreiras arquitetônicas e comunicacionais, como a falta de acesso adequado às salas de exposição, problemas com a altura de expositores e legendas etc.

\section{RESULTADOS E DISCUSSÃO}

O processo de fundação da UFS esteve diretamente ligado ao cenário nacional das décadas de 1960 a 1980 marcado pelas reformas universitárias. A partir da reunião das faculdades já existentes, Dom Luciano Cabral Duarte e outros intelectuais incentivaram o processo de criação da Universidade que foi instaurada em 1968 (ARAÚJO, 2008). Ao longo dos anos o intercurso de consolidação da Universidade foi marcado por diversas iniciativas como a reunião das bibliotecas setoriais (pertencentes às faculdades) em um único espaço, a instalação de refeitórios, laboratórios, a criação de ambientes de convivência e espaços culturais.

$\mathrm{Na}$ atualidade pode-se identificar diversos espaços dedicados à cultura e arte que congregam estudantes, pesquisadores e comunidades com a finalidade de discutir, apresentar e estudar a ciência, a cultura, a arte, a memória e a história. Dentre eles destaca-se o Museu de Anatomia, o Museu do Homem Sergipano, o Museu Arqueológico de Xingó, o CULTART, o Herbário, a Galeria Jordão de Oliveira, o Memorial da Democracia e o Centro de Pesquisa Documentação e Memória do Colégio de Aplicação (CEMDAP). 
Entre os espaços citados, há algumas instituições que, apesar de vinculadas à UFS, não estão instaladas dentro do campus universitário, como é o caso do Museu Arqueológico de Xingó (MAX), o CULTART e o Museu do Homem Sergipano. Entretanto eles têm um papel fundamental na produção de conhecimento científico por meio das pesquisas que são realizadas com os acervos museológicos tanto pela graduação quanto pela pós-graduação, na difusão da informação pelas ações de extensão e na aplicação de ações culturais e educativas, visando a formação e desenvolvimento cultural dos visitantes.

Desta forma, por sua importância na difusão da cultura e da história sergipana, bem como suas particularidades arquitetônicas, foram selecionadas para a presente análise. Salienta-se que as instituições escolhidas para este estudo, assim como nenhuma outra do estado de Sergipe, não estão no Guia de Museus e Centros de Ciências Acessíveis da América Latina e Caribe (ROCHA et al., 2017), que apresenta a acessibilidade de 110 espaços científico-culturais.

O MAX foi criado em $2000 \mathrm{com}$ o intuito de preservar a cultura material xingoana encontrada na região do baixo São Francisco, afirma Diniz (2005). De acordo com essa autora, foi a partir de 1988, juntamente com a construção da Hidrelétrica de Xingó que um projeto de salvamento arqueológico foi chefiado pela UFS com o apoio da Companhia Hidroelétrica de São Francisco (CHESF), permitindo o salvamento de fósseis e artefatos datados em mais ou menos 9.000 anos (DINIZ, 2005).

O MAX tem desenvolvido ações que vão para além da visita técnica ao acervo, como projetos culturais e educativos, principalmente voltados para a comunidade local e escolar com vistas a implementar uma consciência sobre a pré-história sergipana e sobre a necessidade de preservação do patrimônio cultural sergipano. A exposição de longa duração, as exposições temporárias ou as itinerantes tomam como foco principal a representação do 'Homem de Xingó' que, de acordo com Nunes (2001, p.127), essa discussão tem como objetivo “apresentar a história dos 'povos sem história”.

A partir desse mote, a expografia narra o processo das primeiras ocupações, as atividades sociais, as produções em cerâmica, os ritos funerários, tendo como base os objetos de cultura material coletados. Esses objetos, produtos de uma cultura e uma determinada sociedade são utilizados como suporte da informação para narrar modos de vida que, no âmbito o museu constitui o que é denominado objeto de museu.

O MAX, como um dos poucos espaços culturais sergipanos que teve sua edificação construída especificamente para servir como museu, apresenta na sua estrutura física a maioria dos requisitos exigidos pelas normativas de acessibilidade física, inclusive as orientações presentes na Norma NBR ABNT 9050. A instituição apresenta rampas de acesso adequadas, sem desníveis significativos no interior da instituição, com piso adequado e banheiro adaptado.

Entretanto, carece da implementação de dispositivos complementares que ajudem no processo de inclusão, como os apontados por Takiuchi (2019), a exemplo, pisos táteis, cadeiras de rodas, mapas táteis da exposição e mapas táteis de localização. Takiuchi (2019, p. 45) relata que “[...] nos museus há uma predominância da utilização dos receptores distantes, que lidam com o exame de objetos à distância, havendo uma maior exploração visual e auditiva, que contribui com a criação de uma barreira comunicacional [...]". 
Em relação à acessibilidade comunicacional percebemos que o MAX disponibiliza diversos recursos que são auxiliares no processo de apropriação do conhecimento e que também melhoram a experiência da visita. Mas ao realizar um diagnóstico de acessibilidade da expografia do MAX, com base nas teorias da Arqueologia Sensorial, Takiuchi (2019) apontou algumas barreiras para a acessibilidade comunicacional como: ausência de legendas em Braille e de textos adaptados, ausência de tradutores de Libras e inadequação de alguns mobiliários.

Apesar de parte do acervo estar disponível para o toque, muitos artefatos não tinham réplicas e/ou eram considerados frágeis, considera Takiuchi (2019). Quando avaliamos a acessibilidade comunicacional de uma exposição, consideramos atividades que envolvem o toque. Entretanto, entendemos que o toque seja uma parte importante no processo de compreensão das informações ali presentes, mas não necessariamente a única opção. É possível também articular outras opções como audioguias, audiodescrição, relatos de experiências, depoimentos gravados, textos e figuras em braille e baixo relevo.

Outras sensações também podem ser desenvolvidas para estimular o envolvimento dos visitantes como sons, músicas, cheiros que contextualizam e que também promovam situações de aprendizagem e entretenimento. No entanto, apesar das dificuldades encontradas, o MAX consegue promover a aproximação dos visitantes mediante ações culturais e educativas que extrapolam as barreiras da expografia por meio do toque em algumas peças do acervo e pela mediação realizada pelos funcionários da instituição.

Já o Centro de Cultura e Arte (CULTART) surgiu por volta da década de 1980 como um órgão da UFS vinculado à Pró-Reitoria de Extensão, com a missão de implementar ações para a preservação e promoção da produção artística e cultural de Sergipe2. Está instalado no prédio da antiga Faculdade de Direito, datado do início do século XX, que foi adaptado para promover as ações culturais e artísticas da UFS e está localizado no centro da cidade de Aracaju, capital. Construído na "Rua da Frente"3 a monumentalidade do prédio, como demonstra a Figura 1, é típica das construções escolares das primeiras décadas republicanas, garantindo sua visibilidade por quem passa por perto.

Assim, podemos perceber que diferentemente do Museu de Xingó, o CULTART não foi edificado com a finalidade de ser um espaço cultural. Além desse fato, entre o final do século XIX e início do XX as construções não previam medidas de inclusão social e nem os Códigos de Postura estabeleciam determinações nesse sentido. Assim, não é incomum encontrarmos prédios adaptados ou em processo de adaptação para atender as exigências atuais de acessibilidade. Não foi diferente com o prédio do CULTART. Em reformas posteriores a sua instalação, construiu uma rampa de acesso localizada no fundo do prédio. A escadaria que dá acesso à parte interna continuou sem modificações devido a impossibilidade de mudança na fachada do prédio.

2 http://cultart.ufs.br/pagina/416

3 Avenida Ivo do Prado, conhecida como Rua da Frente. 
Figura 1 - Fachada do CULTART-UFS. Aracaju,1914-1915

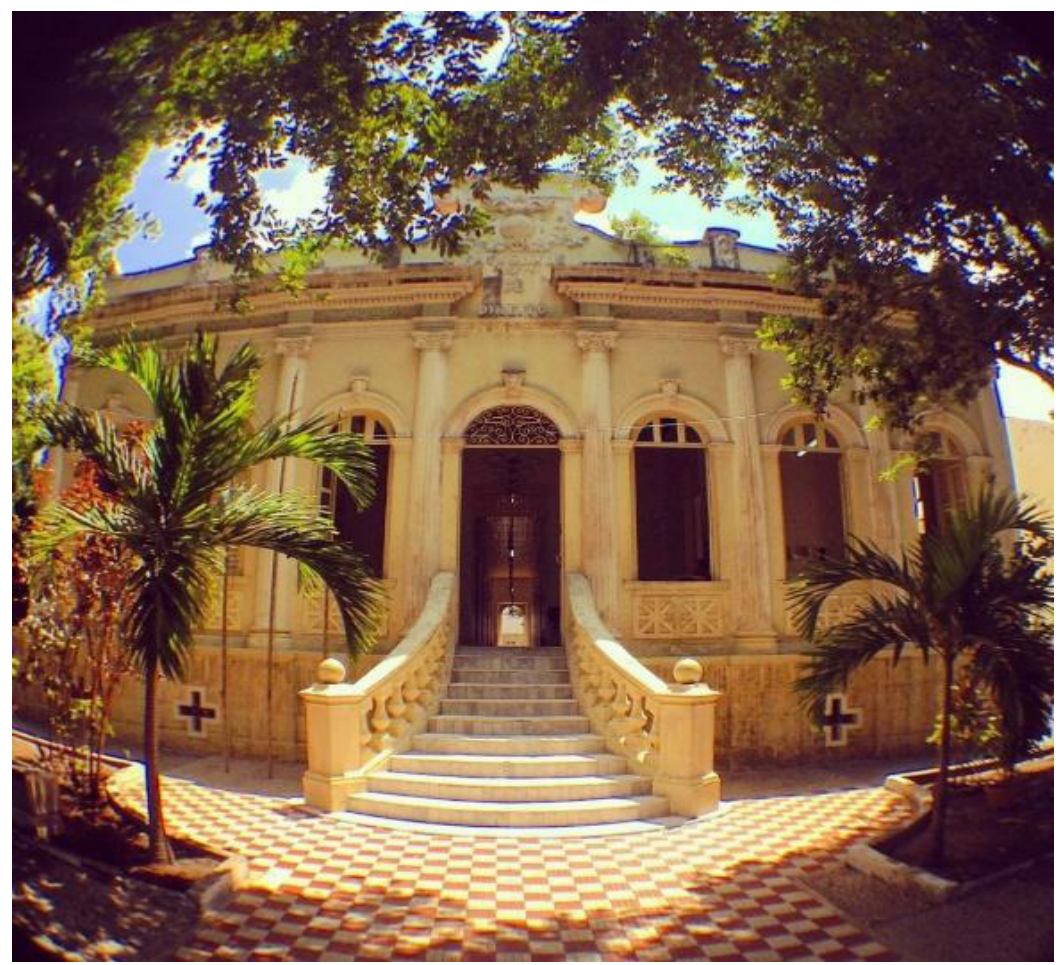

Fonte: Luís Américo Bonfim.

Ao visualizarmos a imagem podemos perceber que se trata de um prédio que apresenta vários elementos que remetem ao estilo neoclássico, como a fachada equilibrada de forma simétrica, com meias colunas em estilo jônico com capitel, o CULTART se encontra no circuito turístico de Aracaju, ficando próximo ao Museu da Gente Sergipana, o Largo da Gente Sergipana, o Museu da OAB, o Centro Cultural de Aracaju, Memorial Zé Peixe, Palácio Museu Olímpio Campos e o Mercado Municipal de Aracaju. Sua estrutura foi adaptada para receber as funções administrativas e expositivas, na qual se contabiliza três salas expositivas, sendo a primeira dedicada às exposições temporárias que normalmente são submetidas a editais e abertas à comunidade universitária e ao público em geral; uma galeria e uma pinacoteca. Ao fundo tem um palco onde são promovidos festivais e um anexo mais recente com laboratórios e salas de aula.

Quando realizada a verificação da acessibilidade física e comunicacional percebeu-se que algumas dificuldades encontradas são comuns aos prédios históricos que são adaptados para servir como espaços culturais. Como um típico prédio escolar do início do século XX, ele apresenta uma arquitetura peculiar com um átrio, seguido por uma escadaria que dá acesso ao interior. Com as novas determinações legais, o prédio passou por reformas estruturais para adequação da acessibilidade física. 
Com as adequações foi instalada uma rampa de acesso no fundo do prédio de acordo com os padrões exigidos e adaptações nos banheiros.

Assim, para Sarraf (2008) a acessibilidade só acontece quando tanto os equipamentos, os instrumentos de comunicação, quanto os espaços físicos podem ser utilizados com segurança e autonomia pelos visitantes independente se suas condições:

Acessibilidade em museus significa que as exposições, espaços de convivência, serviços de informação, programas de formação e todos os demais serviços básicos e especiais oferecidos pelos equipamentos culturais devem estar ao alcance de todos os indivíduos, perceptíveis a todas as formas de comunicação e com sua utilização de forma clara, permitindo a autonomia dos usuários. Os museus para serem acessíveis, portanto, precisam que seus serviços estejam adequados para serem alcançados, acionados, utilizados e vivenciados por qualquer pessoa, independente de sua condição física e comunicacional. (SARRAF, 2008, p. 38).

Ao se analisar o espaço do CULTART e sua reforma percebe-se que não houve uma preocupação em oferecer instrumentos mais flexíveis e intuitivos para facilitar o uso do espaço e consumo da exposição como textos em Braille, audioguias, audiodescrição, mapas táteis, piso táteis, entre outros.

O Museu do Homem Sergipano apresenta uma particularidade, seu prédio ao ser interditado para visitação pública em 2011, suspendendo em definitivo as atividades internas no ano de 2014, teve seu acervo emprestado para duas outras instituições com a finalidade de que o público continuasse a ter acesso aos bens culturais. Seu acervo encontra-se parte em exposição no Museu Histórico de Sergipe, desde o ano de 2017, em São Cristóvão, e outra parte no Laboratório de Expografia do curso de Museologia/UFS, no campus de Laranjeiras, para estudo e produção de exposições temporárias.

Inicialmente denominado Museu de Antropologia, conforme aponta Nunes (2010), o espaço nasceu como um órgão vinculado à Pró-Reitoria de Extensão (PROEX), em 1978. De 1983 até os anos de 1988, o museu passou a funcionar no CULTART quando então foi nomeado "Sala de Cultura Popular", o qual apresentava exposições sobre o artesanato sergipano, objetos que compõem até hoje o acervo da instituição. Posteriormente foi agregado por um departamento da área da saúde, onde passou a ser designado como Núcleo Museológico.

Lembra Nunes (2010) que o Museu do Homem Sergipano, em 2004, foi transferido para a antiga Faculdade de Serviço Social, um prédio datado da década de 1920, e apresentou uma narrativa expositiva que teve como inspiração o livro Textos para a história de Sergipe, organizado por Diana Diniz (2013). Como parte de sua política de aquisição, o museu agregou diversas coleções que representavam a história e trajetória do homem sergipano na área social, econômica, política e cultural. Por problemas estruturais, o museu teve que fechar suas portas por tempo indeterminado, mas não deixou de servir ao seu propósito.

Num olhar mais criterioso, observa-se os problemas estruturais de acesso ao prédio do Museu Histórico de Sergipe, com escadarias e desníveis na parte interna do prédio, banheiros com adaptações pendentes e falta de monitoria capacitada para atender a todos os tipos de público. Nesse 
espaço foi construída uma narrativa expositiva que buscou retratar dois temas da história de Sergipe: o ambiente doméstico, representado pela Casa Grande e a economia sergipana.

Estão expostos elementos marcantes da economia açucareira, da pecuária e agricultura sergipana estão representados pelas cangas de boi, arados, pilões e pelos tachos onde o caldo da cana virava açúcar. Foram implementados $Q R$ Codes para facilitar o acesso às informações, mas, apesar do que foi feito, ainda é preciso desenvolver mecanismos mais assistivos, flexíveis e intuitivos para atender às necessidades dos visitantes. A criação de textos em Braille, em alfabeto manual e audiodescrição poderiam ser ações plausíveis para implementar o acesso a todos.

\section{CONCLUSÃO}

Os museus como espaços de informação e a serviço da sociedade em geral devem buscar sua aproximação com seus públicos, o que é feito, em um primeiro momento, pelas exposições. Mas, para receber esses públicos, o museu deve estar apto a minimizar as barreiras físicas e comunicacionais, possibilitando a sua ampla vivência e experimentação.

Ao realizarmos a análise desses espaços da Universidade Federal de Sergipe, mais que uma crítica, visamos uma reflexão sobre o papel dessas instituições e como elas hoje estão recebendo seus visitantes. A partir dessas observações podemos pensar em soluções práticas que viabilizem a implementação do desenho universal. Verificamos que os espaços culturais da UFS carecem de elementos que caracterizam o desenho universal, o que dificulta a acessibilidade em alguns edifícios ou espaços. As barreiras arquitetônicas são as mais perceptíveis, contudo, foi constatado a falta de recursos interativos nas exposições, caracterizando uma barreira atitudinal.

A Universidade tem condições de disponibilizar tradutores em Libras para eventos com a presença de deficientes auditivos, existe a possibilidade de oferecer estágios para estudantes de Libras nesses espaços, estimular a produção de projetos de pesquisa e extensão com foco na inclusão cultural nos museus da UFS, é possível também de desenvolver projetos tecnologia, pensando em dispositivos assistivos para as exposições. Além disso, há recursos humanos para a realização de gravação de vídeos em Libras, produção de maquetes táteis das plantas baixas dos prédios, bem como a possibilidade de impressão em Braille dos folders, etiquetas e material de apoio, ou ainda, a tradução para outros idiomas para tornar a exposição mais acessível ao máximo de visitantes, independentemente da barreira linguística.

A implementação de políticas assistivas no âmbito dos museus da UFS possibilita que todos se beneficiem dos recursos. Ao permitir que esses espaços culturais se tornem mais sensíveis, os profissionais de museus podem proporcionar novas experimentações por meio de distintas formas de aprendizagem e vivências, para além do visual, permitindo novas formas de se relacionar com os objetos e o espaço cultural. 


\section{REFERÊNCIAS}

ARAÚJO, Gerry Sherlock. A instalação da Universidade Federal de Sergipe: o ensino de graduação sob o signo da reforma universitária. Congresso Brasileiro de História da Educação, 5, Universidade Federal de Sergipe; Universidade Tiradentes. Anais [...], São Cristóvão; Aracaju, 2008. Disponível em: http://www.sbhe.org.br/novo/congressos/cbhe5/pdf/154.pdf. Acesso em: 16 maio 2020.

BRASIL. Lei n⿳0 13.146, de 6 de julho de 2015. Institui a lei brasileira de inclusão da pessoa com deficiência (estatuto da pessoa com deficiência). Brasília, 2015. Disponível em: http://www. planalto.gov.br/ccivil_03/_ato2015-2018/2015/Lei/L13146.htm. Acesso em: 26 dez. 2020.

BRASIL. Decreto 5296, de 2 de dezembro de 2004. Prioridade de atendimento às pessoas que especifica, e estabelece normas gerais e critérios básicos para a promoção da acessibilidade das pessoas portadoras de deficiência ou com mobilidade reduzida. Presidência da República. Casa Civil. República Federativa do Brasil, Poder Executivo, Brasília, DF. Disponível em: http://www. planalto.gov.br/ccivil_03/_ato2004-2006/2004/decreto/d5296.htm. Acesso em: 28 out. 2016. BRASIL. Instituto do Patrimônio Histórico e Artístico Nacional. Instrução Normativa nº 1, 25 de dezembro de 2003. Disponível em: http://www.comphap.pmmc.com.br/arquivos/lei_federal/ instrucao_01_2003.pdf. Acesso: 1jun. 2020.

BRASIL. Lei no 10.098, de 19 de dezembro de 2000. Estabelece normas gerais e critérios básicos para a promoção da acessibilidade das pessoas portadoras de deficiência ou com mobilidade reduzida, e dá outras providências.Disponível em: http://www.planalto.gov.br/ccivil_03/leis/l10098. htm. Acesso em: 10 maio 2020.

CAMARGO, Eder Pires de. Inclusão social, educação inclusiva e educação especial: enlaces e desenlaces. Ciênc. educ., Bauru, v. 23, n.1, jan./mar. 2017.

CARVALHO, Angela Costa Werneck de. Desenho universal, acessibilidade e integração modal, estudo exploratório no transporte coletivo no Rio de Janeiro. 2005. Dissertação (Mestrado em Ciências em Engenharia de Transportes) - Programas de Pós-Graduação de Engenharia, Universidade Federal do Rio de Janeiro, Rio de Janeiro, 2005.

CIANTELLI, Ana Paula Camilo; LEITE, Lúcia Pereira. Ações Exercidas pelos Núcleos de Acessibilidade nas Universidades Federais Brasileiras. Rev. Bras. Ed. Esp., Marília, v. 22, n. 3, p. 413428, jul./set. 2016.

DINIZ, J. A. F. Uma nova realidade museal em Sergipe: o Museu de Arqueologia de Xingó. Revista da Fapese de Pesquisa e Extensão, v. 1, p. 63-72, mar./jun. 2005. 
HUGHES, Philip. Diseño de exposiciones. Barcelona: Promopress, 2010.

MARTINS, Patrícia Roque. Museus (IN)capacitantes: deficiência, acessibilidades e inclusão em museus de arte. Portugal: Caleidoscópio - edição de artes gráficas, SA. 2017.

NORBERTO ROCHA, Jessica et al. Guia de museus e centros de ciências acessíveis da América Latina e do Caribe. Rio de Janeiro: Museu da Vida/ Casa de Oswaldo Cruz/Fiocruz: RedPOP; Montevidéu: Unesco, 2017.

NUNES, Verônica Maria M. Museu de Arqueologia de Xingó: nota sobre o discurso expositivo. Revista do Museu Arqueológico de Xingó, n. 1, p. 2, dez. 2001.

NUNES, Verônica Maria M. O Museu do Homem Sergipano. Patrimônio e memória, UNESP FCLAs - CEDAP, v. 6, n. 2, p. 67-85, dez. 2010. Disponível em: http://pem.assis.unesp.br/index.php/ pem/article/view/87/556. Acesso em: 16 maio 2020.

\section{REIS, Rosana Santana dos. Acessibilidade a edifícios históricos de interesse turístico} por pessoas com mobilidade reduzida: um estudo de exemplos representativos situados na Rota Acessível do Centro Histórico de Salvador. 2015. Dissertação (Mestrado em Arquitetura e Urbanismo) - Universidade Federal da Bahia, 2015.

RIBEIRO, Felipe Gomes. Acessibilidade em espaço universitário: barreiras arquitetônicas e ambientais no campus da Universidade Estadual de Feira de Santana. 2014. Dissertação (Mestrado em Desenho, Cultura e Interatividade) - Universidade Estadual de Feira de Santana, Feira de Santana, 2014.

SALASAR, Desireé Nobre; MICHELON, Francisca Ferreira. Os museus federais e as barreiras de acessibilidade comunicacional. Anais da Semana de Museus da UFPEL, v. 4, p.134-144, 2020. e-ISSN - 2674-6298

SAGAN, Carl. O mundo assombrado pelos demônios: a ciência vista como uma vela no escuro. Trad. Rossaura Eichemberg. São Paulo: Companhia das Letras, 1996.

SARRAF, Viviane Panelli. Reabilitação do museu: políticas de inclusão cultural por meio de acessibilidade. 2008. Dissertação (Mestrado em Ciência da Informação) Programa de Pós-graduação em Ciência da Informação, Escola de Comunicações e Artes, Universidade de São Paulo, São Paulo, 2008. 
SASSAKI, R. K. Inclusão: acessibilidade no lazer, trabalho e educação. Revista Nacional de Reabilitação (Reação), São Paulo, Ano XII, p. 10-16, mar./abr. 2009. Disponível em: https://files. cercomp.ufg.br/weby/up/211/o/SASSAKI_-_Acessibilidade.pdf?1473203319. Acesso: 20 maio 2020.

SASSAKI, Romeu Kazumi. Inclusão: construindo uma sociedade para todos. Rio de Janeiro: WVA, 2010.

STAUT, Lucy Ana Vilela. Usabilidade universal da arquitetura: método de avaliação baseado em heurísticas. 2014. Dissertação (Mestrado em Arquitetura, Tecnologia e Cidade) - Universidade Federal de Campinas, Campinas, 2014.

TAKIUCHI, Tatiane Mie. Acessibilidade do conhecimento arqueológico em Sergipe: uma nova abordagem para o Museu de Arqueologia de Xingó. 2019. Trabalho de Conclusão de Curso -TCC (Graduação em Arqueologia) - Departamento de Arqueolgia, UFS, Laranjeiras, 2019.

TOJAL, Amanda Pinto da Fonseca. Políticas públicas culturais de inclusão de públicos especiais em museus. 2007. Tese (Doutorado em Ciência da Informação) - Escola de Comunicações e Artes, Universidade de São Paulo, São Paulo, 2007. 
1 Professora Associada do Departamento de Museologia da Universidade Federal de Sergipe, Coordenadora do Laboratório de Museologia Aplicada (LabMusas), Líder do Grupo de Estudos e Pesquisas em Memória e Patrimônio Sergipano (GEMPS/UFS/CNPq). e-mail: tina_valenca@ yahoo.com.br

2 Professora Adjunta do Departamento de Museologia da Universidade Federal de Sergipe, Coordenadora do Laboratório de Expografia (LabExpo), Vice-Líder do Grupo de Estudos e Pesquisas em Memória e Patrimônio Sergipano (GEMPS/UFS/CNPq). e-mail: priscilamdj@gmail.com

3 Professora Adjunta do Departamento de Museologia da Universidade Federal de Sergipe, Membro do Grupo de Estudos e Pesquisas em Memória e Patrimônio Sergipano (GEMPS/UFS/CNPq).e-mail: suracarmo@yahoo.com.br

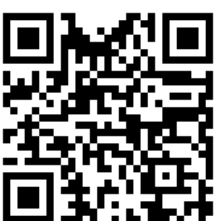

A autenticidade desse artigo pode ser conferida no site https://periodicos. set.edu.br

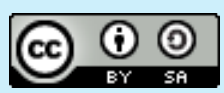

Este artigo é licenciado na modalidade acesso abertosob a Atribuição-Compartilhalgual CC BY-SA

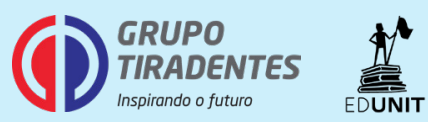

